\title{
A UTILIZAÇÃO DE VIDEOCLIPES COMO INSTRUMENTO EM BUSCA DA MOTIVAÇÃO NAS AULAS DE LÍNGUA INGLESA
}

\author{
Rayanne Rodrigues dos SANTOS \\ Universidade Federal do Amapá \\ Alan Willin Pereira da SILVA \\ Universidade Federal do Amapá \\ Wesley Fernando Marques dos SANTOS \\ Universidade Federal do Amapá \\ Silvagne Vasconcelos DUARTE \\ Universidade Federal do Amapá
}

RESUMO: Apesar da sua crescente circulação social e popularização nos meios de comunicação de massa (televisão, internet e variados dispositivos eletrônicos móveis, tais como tablets e celulares), o gênero videoclipe ainda não tem recebido a devida atenção das pesquisas linguísticas e discursivas, principalmente, no que tange o ensino-aprendizagem de línguas. Este trabalho lança mão dos estudos dos multiletramentos, da multimodalidade textual, das estratégias de aprendizagem e da motivação com o propósito de estabelecer uma categorização das configurações genéricas dos videoclipes. O objetivo é verificar as potencialidades do videoclipe como instrumento de ensino-aprendizagem na aula de língua inglesa, em que acreditamos que o uso desse gênero pode contribuir para o envolvimento dos alunos com atividades na língua-alvo, influenciando positivamente na motivação dos estudantes que, diante da situação de desprestígio do ensino de inglês, acabam se desinteressando pela aprendizagem. Do ponto de vista teórico, situamo-nos na pesquisa de Rojo (2009, 2012, 2013), O’Malley e Chamot (1993), Oxford (1990), Dörnyei (2001) e dentre outros autores que discutem a utilização de gêneros multimodais e de estratégias de aprendizagem nas aulas de línguas, para que o professor e o aluno trabalhem em conjunto na promoção de motivação, já que processo de aprendizagem está conectado às motivações pessoais, aspirações e desenvolvimento que o aluno perpassa para alcançar seu objetivo em algo que queira aprender. Para conseguir resultados desta pesquisa, desenvolvemos uma pesquisa-ação em aulas do segundo ano do ensino médio de escola pública. Algumas considerações provenientes dessa pesquisa, que foi construída a partir de um método qualitativo-quantitativo, apontam para uma reflexão a respeito da utilização do videoclipe como um recurso motivador nas aulas de língua inglesa.

PALAVRAS-CHAVE: Ensino-aprendizagem da língua inglesa. Videoclipes. Motivação.

ABSTRACT: Despite its growing social circulation and popularity of mass media (television, internet and various mobile electronic devices such as tablets and mobile phones), the video clip genre has not received due attention of linguistic and discursive research, especially in regarding the teaching and learning of languages. This article makes use of studies of multiliteracies, textual multimodality of learning strategies and motivation in order to establish a categorization of generic settings of video clips. The objective of this study is to verify the video clip's potential as a teaching and learning tool in English class, we believe that the use of this resource can help to the interactivity of students with activities in the target language, influencing positively on student motivation which, given the disrepute situation of English teaching, end up losing interest in learning. From a theoretical point of view, we are situated in researches of Rojo (2009, 2012, 2013), O'Malley and Chamot (1993), Oxford (1990), Dörnyei (2001), among other authors who discuss the use of multimodal genres and learning strategies in language classes so that the teacher and student can work together to promote motivation, since learning process personal motivations are connected, 
aspirations, actions and development that the student goes through to reach your goal in anything it want to learn. To achieve results of this research, we have developed an action research in classes of second grade of high school public school. Some considerations from this research, built with a qualitative and quantitative method, aim for a reflexion about the use of videoclip as a motivacional resource in the english language classes.

KEYWORDS: Teaching and learning of English. Videoclips. Motivation.

\section{Introdução}

Com sua crescente popularização nos meios de comunicação de massa, sobretudo a partir dos anos 1980, os videoclipes tornaram-se um dos principais gêneros midiáticos de expressão cultural e estética da contemporaneidade. As novas Tecnologias de Informação e Comunicação (TIC) estabelecem algumas práticas letradas que invadem o cotidiano de alunos, exigindo a aquisição e desenvolvimento de leitura e escrita através de textos multimodais multissemióticos que combinam imagens estáticas ou em movimento, com áudio, e vídeos - em que se inserem os videoclipes - em que torna o ambiente digital atrelado ao ambiente escolar.

Nas aulas de Língua Inglesa a investigação sobre o que os motive a aprender é imprescindível para que o professor tenha em mãos possíveis instrumentos de trabalho para facilitar no processo de ensino-aprendizagem, pois a razão da aprendizagem pode ser encontrada por este aluno através do que ele gosta na Língua Inglesa, e os videoclipes, que fazem parte do universo dos jovens do ensino médio, podem ser um instrumento motivador para auxiliar nessa aprendizagem. O professor pode tomar o sentido da autonomia para que este aluno continue cada vez mais buscando a aprender algo que o desperte dentro do Inglês como língua estrangeira. A ligação entre a motivação e a autonomia conectadas através dos aspectos que fazem os alunos aprenderem, leva então, o professor a incentivar o aluno a cada vez mais explorar para si a aprendizagem da língua inglesa. A utilização de videoclipes em sala de aula, tomando como um gênero multimodal pode ser explorado e, com o uso de estratégias de aprendizagem, pode ser eficiente na aquisição da língua inglesa.

\section{$O$ videoclipe na perspectiva dos multiletramentos}

Há uma múltipla exigência das práticas de linguagem na contemporaneidade, visto que são novas as relações multiculturais entre o global e local, valorizado e não valorizado. Assim, vemos a necessidade de abrir novos caminhos de aprendizagem dos alunos, ampliando o conhecimento sobre determinado assunto. Lemke (2010[1998] apud ROJO, 2012) nos dá um breve entendimento sobre essa nova forma

[...]Agora a aprendizagem muda. Em vez de sermos prisioneiros de autores de livros-textos e de suas prioridades, escopos e sequência, somos agentes livres que podem encontrar mais sobre um assunto que os autores sintetizaram [...] podemos mudar o assunto para adequá-lo ao nosso juízo de relevância para nossos próprios interesses e planos e podemos retornar mais tarde para um desenvolvimento padrão baseado no livro-texto. (p.21).

Trazendo a perspectiva da língua inglesa para a realidade dos multiletramentos, podemos trabalhar a criação de sentidos para a língua, tornando ampla a necessidade de se 
usar métodos que englobem o cotidiano dos alunos, que possam se desvincular da gramática normativa, e utilizar a língua inglesa em contextos variados.

No campo específico dos multiletramentos, isso implica negociar uma crescente variedade de linguagens e discursos: interagir com outras línguas e linguagens, interpretando ou traduzindo, usando interlínguas específicas para certos contextos, usando o inglês como língua franca; criando sentido da multidão de dialetos, acentos, discursos, estilos e registros presentes na vida cotidiana, no mais pleno plurilinguismo bakhtiniano. Ao invés da gramática como norma para a língua padrão, uma gramática contrastiva que, como Ártemis, permite atravessar fronteiras. (ROJO,2013, p.17)

Ou seja, o aluno pode buscar aprender uma língua através de diversas práticas de seu cotidiano que não estão ligadas a gramática para que se haja normas para sua aprendizagem, tornando sua forma de aprender prazerosa, que pode levá-lo a buscar mais determinado conteúdo por simplesmente estar motivado para tal.

Percebemos as grandes mudanças na maneira de ler, produzir e fazer circular informações na sociedade, em que grande parte dessa evolução vem do público jovem, fazendo disso uma prática multiletrada. Os videoclipes circulam nas redes sociais de forma intensa, fazendo os jovens compartilharem constantemente esse tipo de mídia.

\begin{abstract}
Mudam os modos de ler ao longo do tempo, exatamente porque mudam também os modos de vida das pessoas e, portanto, os modos como interagem com os materiais escritos. Assim, junto com as práticas de letramento, mudam os gêneros discursivos e surgem novos gêneros. Esses novos gêneros são criados a partir de gêneros já existentes". (SOUZA; CORTI; MENDONÇA, 2012,p.33)
\end{abstract}

Assim, os modos de propagar informações estão ligados aos modos de vida das pessoas, e é o que acontece no universo dos jovens, em que, atualmente, são os responsáveis por essas mudanças, principalmente nas mídias e redes sociais.

O distanciamento de meios impressos dos meios digitais é dado a partir das mudanças nos meios de comunicação, fazendo surgir novos gêneros, em que os jovens também fazem parte da ampliação de contínuos de acesso às tecnologias utilizadas na comunicação e informação. Já não basta mais apenas a leitura do texto verbal escrito, há a necessidade de se vincular com outras formas de significar, outras modalidades de linguagem. Rojo (2013) os chama de "novos escritos"

Esses "novos escritos" obviamente dão lugar a novos gêneros discursivos quase diariamente: chats, páginas, twits, posts, ezines, epulps, fanclips etc. E isso se dá porque hoje dispomos de novas tecnologias e ferramentas de "leitura-escrita", que, convocando novos letramentos, configuram os enunciados/textos em sua multissemiose ou em sua multiplicidade de modos de significar. (ROJO, 2013, p.20, grifo da autora)

Ao colocar o videoclipe como um desses "novos escritos", é possível afirmar que a utilização dele em uma prática multiletrada para o ensino-aprendizagem da língua inglesa é válida, já que o componente visual faz parte de um conjunto de signos que auxiliam tanto no entendimento de algumas palavras, quanto na construção de sentido do vídeo, pois a 
gramática não está em foco neste caso. A importância de trabalhar estas práticas em sala de aula baseia-se na democratização do ensino e da aprendizagem, já que, como afirma Dias (2012, p.99-100), "um dos letramentos muitas vezes relegado a segundo plano nas esferas escolares é aquele que capacita o aluno a promover sentidos e a interagir com os gêneros digitais presentes nos ambientes tecnológicos aos quais os internautas têm acesso".

\section{O videoclipe como gênero multimodal}

As crescentes buscas por gêneros que reúnam diversas linguagens é algo impossível de ignorar. Os gêneros multimodais circulam em nosso cotidiano de maneira recorrente e nem sempre nos damos conta do quanto eles estão impregnados em diversas situações comunicativas. A globalização e as inovações tecnológicas moldam as práticas discursivas, e as escolas veem-se imersas nelas, e com muita frequência, alunos utilizam dos meios eletrônicos e tecnológicos para cumprir seu papel de cidadão na sociedade. Nesse momento, em que vemos os alunos no espaço da cibercultura, é necessário verificar a oportunidade favorável para que se encontrem as situações propícias, e que as inúmeras manifestações e utilizações tecnológicas venham ao encontro com a sala de aula, na expectativa de fazer dos referidos meios, oportunidades de interação com seus interlocutores de modo oral e pessoal. Como diz Lemke (2010[1998] apud ROJO 2012, p.26-27), "precisamos pensar um pouco sobre como as novas tecnologias da informação podem transformar nossos hábitos institucionais de ensinar e aprender".

Seguindo a mesma visão de Rojo (2013) em relação ao gêneros multissemióticos, a introdução de novos e outros gêneros de discurso por novas mídias, tecnologias e linguagens colocam alguns questionamentos para a teoria dos gêneros do discurso do Círculo de Bakhtin. Por mais que Bakhtin tenha privilegiado textos escritos e impressos em sua rica produção, podemos considerar o conceito de gênero discursivo (BAKHTIN, 1997), que centrava-se em análises de situações de produção de enunciados ou textos e seus aspectos sócio-históricos. Em nosso cotidiano, passamos por diversas esferas de comunicação (escolar, familiar, jornalística, publicitária etc) em diversas posições sociais, como produtores/receptores dos discursos, em gêneros, mídias e culturas diferentes. Estamos considerando que as novas formas de produção e circulação de textos estão ampliando, modificando e reconfigurando as novas formas de fazer textos. Sendo assim, podemos considerar que a teoria dos gêneros continua atual e relevante, em que uma das grandes contribuições é quando alega que "a variedade virtual da atividade humana é inesgotável, e cada esfera dessa atividade comporta um repertório de gêneros do discurso que vai diferenciando-se e ampliando-se à medida que a própria esfera se desenvolve e fica mais complexa". (BAKHTIN, 1997, p.280). Isso permite aberturas para as novas formas de linguagens, suportes, esferas e hibridismos de toda ordem. (NETO et al, 2013, p. 139)

Essa teoria permite aplicar aos objetos de aprendizagem em ambiente digital, principalmente porque há uma perspectiva dialógica da linguagem. Rojo (2013) ainda reforça que não há impedimentos para a aplicação dessa teoria quando se tratam de textos contemporâneos, multissemiótico ou multimodais

Consideremos, por um momento, as novas formas de produção, configuração e circulação dos textos, que implicam multiletramentos. As mudanças relativas aos meios de comunicação e à circulação de informação, o surgimento e a ampliação de contínuos de acesso às tecnologias digitais da comunicação e da informação provocaram a intensificação vertiginosa e a diversificação da circulação da informação nos meios de comunicação 
analógicos e digitais, que, por isso mesmo, distanciam-se hoje dos meios impressos, muito mais morosos e seletivos [...] (grifos da autora) (ROJO, 2013, p.19)

Portanto, as mídias e as tecnologias podem fazer parte do discurso, uma vez que eles modificam os gêneros, selecionando diferentes recursos semióticos e diversas combinações possíveis entre eles para atingir suas finalidades e refletir suas temáticas. Rojo (2013, p.29) conclui então que "as mídias e as tecnologias são escolhas, e de caso bem pensado, das esferas de circulação de discurso. Mas têm, de imediato, efeito nas formas de composição e nos estilos dos enunciados, inclusive em termos de multimodalidade."

A nossa sociedade está cada vez mais "visual" e não se contenta mais apenas com a leitura de um texto escrito. Com o advento das tecnologias digitais, imagem e palavra mantém uma relação cada vez mais integrada.

\section{A utilização de estratégias de aprendizagem nas aulas de língua inglesa}

O aluno, ao procurar aprender uma língua, sempre formula meios que o ajudem a compreender as informações, que tornam os caminhos mais viáveis para o aprendizado. $\mathrm{O}$ uso de estratégias de ensino é uma forma também encontrada pelos profissionais para que os alunos estejam em contato com a língua inglesa. Além disso, o uso dessas estratégias pode ser contextualizado de acordo com a necessidade, condição social e, principalmente com o grau de motivação que cada aluno apresenta ao longo da aprendizagem.

Segundo Weinstein e Mayer (1986, p. 315, apud O'MALLEY; CHAMOT, 1990, p.42), o objetivo na utilização de estratégias é "atingir a motivação do aprendiz ou o estado afetivo, ou o jeito que cada aprendiz seleciona, adquire, organiza ou integra um novo conhecimento". Assim, Oxford (1990) nos dá uma definição de estratégias de aprendizagem

Estratégias de aprendizagem são passos que os estudantes utilizam para ampliar sua própria aprendizagem. Estratégias são especialmente importantes para o aprendizado da língua porque eles são ferramentas para ativar, auto-direcionadas para envolvimento, que é essencial para o desenvolvimento da competência comunicativa. Estratégias de aprendizagem de línguas apropriadas resultam na melhora da proficiência e aumenta a auto-confiança. (OXFORD, 1990, p.1. Tradução nossa). ${ }^{1}$

Para O'Malley e Chamot (1990, p. 44), as estratégias são ferramentas para envolvimento ativo e auto-direcionado necessário para o desenvolvimento da habilidade comunicativa em uma segunda língua. Percebemos que as pesquisas na área demonstram que o uso consciente e articulado de estratégias está relacionado ao alcance da proficiência em língua estrangeira.

\footnotetext{
${ }^{1}$ Learning strategies are steps taken by students to enhance their own learning. Strategies are especially important for language learning because they are tools for active, self-directed involvement, which is essential for developing communicative competence. Appropriate language learning strategies results in improved proficiency and greater self-confidence.
} 


\section{A utilização de videoclipes e a motivação na busca da autonomia na aprendizagem de língua inglesa}

Ao ensinar uma língua estrangeira, o professor pretende que os alunos a aprendam de forma duradoura e efetiva. Levar em consideração o conteúdo que o aprendente domina ou não, além do que lhe interessa, é essencial para motivar e envolver. Se os jovens do ensino médio vivem em uma época "visual" e das TIC, os videoclipes que fazem parte de seus cotidianos, quando utilizados em sala de aula, não são totalmente excludentes e podem ser vistos como um instrumento para ser utilizado no processo de motivação.

A motivação é vista na literatura de diversas formas, mas em um consenso geral é descrita como uma força motora que impulsiona o processo de aprender, sem a qual não pode haver sucesso na aprendizagem.

Dörnyei (2001a) chama atenção para o fato de muito ter sido teorizado sobre motivação, mas pouco ter sido salientado com relação à prática, que é o principal questionamento dos professores: afinal, o que deve ser feito para motivar o aluno? Com o propósito de disponibilizar algumas maneiras para suprir essa necessidade de professores e alunos, esse autor criou as estratégias motivacionais.

Para que essas estratégias sejam empregadas com sucesso, segundo Dörnyei (2001a, p.31) algumas condições precisam ser estabelecidas, dada a influência que elas exercem na motivação do aluno:

- Comportamento apropriado do professor e bom relacionamento com os alunos;

- Ambiente agradável de sala de aula;

- Grupo coeso de aprendentes com normas apropriadas.

Para Dörnyei, o papel desempenhado pelo professor é essencial. Segundo ele, é necessário estabelecer uma relação de confiança e respeito entre professor e aluno, cabendo ao primeiro, ao mesmo tempo em que se mostra engajado e animado com seu trabalho, despertar o interesse dos alunos para determinado conteúdo. É também papel do professor planejar as tarefas e administrar a sala de aula.

\section{Metodologia}

Com o consenso entre vários autores, a pesquisa-ação teve seu início através dos trabalhos de Kurt Lewin (1944 apud ANDRÉ, 2012), que já descrevia o processo de pesquisaação e seus traços essenciais como a análise, coleta de dados e conceituação de problemas; planejamento de ação, execução, nova coleta de dados para avaliá-la e a repetição deste ciclo. Esse método teve desenvolvimento com Corey (1953 apud ANDRÉ, 2012) e foi denominada como investigação-ação, descrita como uma ação sistemática e controlada desenvolvida pelo próprio pesquisador.

No método quantitativo, os pesquisadores valem-se de amostras amplas e de informações numéricas, enquanto que no qualitativo as amostras são reduzidas, os dados são analisados em seu conteúdo psicossocial e os instrumentos de coleta não são estruturados. (LAKATOS; MARCONI, 2011, p. 267)

Sobre isso, nos identificamos com os posicionamentos de André (2012) acerca da dicotomia qualitativo-quantitativo:

Posso fazer uma pesquisa que utiliza basicamente dados quantitativos, mas na análise que faço desses dados estarão sempre presentes o meu quadro de referência, os meus valores e, portanto, a dimensão qualitativa. As perguntas que faço no meu instrumento estão marcadas pela minha postura teoria, meus valores, minha visão de mundo. (ANDRÉ, 2012, p 24)

Esta pesquisa foi realizada em uma escola estadual de ensino médio situada no centro da cidade de Macapá, a qual atende a alunos de nível social baixo e médio, residentes no 
mesmo bairro, bairros próximos e até mesmo distantes. A coleta de dados ocorreu durante o período de realização do estágio para o cumprimento das atividades de Estágio Supervisionado, requisito obrigatório do curso de Licenciatura Plena em Letras Português/Inglês. Este estágio foi desenvolvido no mês de março, duas vezes na semana no turno da tarde, em uma turma, totalizando oito horas/aula.

A coleta de dados tem abordagens de cunho interpretativo e requer uma vasta gama de métodos e instrumentos em sua aplicação e percepção, uma vez que as percepções e tentativas de conclusão dos dados pesquisados precisam ser confirmadas ou não por outros pontos de vista. Assim, é possível observar o que as ações das pessoas parecem significar para elas; entretanto, é preciso verificar, através de pesquisas formais e informais, a confirmação desses sentidos. Observações e questionamentos podem gerar diferentes fontes e tipos de dados: notas de campo escritas pelo observador, comentários das entrevistas, gravações que se tornam a base para transcrições de comportamentos verbais e não verbais, cada um apresentando um status epistemológico diferente como evidência, cujo registro se deu através de notas de campo e diários, questionários e entrevistas formais. Nesta perspectiva, nossa pesquisa instrumentaliza a coleta de dados como fundamentação para a motivação no processo de aprendizagem dos alunos do segundo ano do ensino médio da escola pública.

\section{Análise e discussão dos dados}

A análise foi dividida pelos instrumentos de coleta de dados seguidas de comentários sobre a reação dos aprendentes às atividades, vinculados com os registros das notas de campo, ponderando de forma qualitativa e quantitativa conforme proposto na Metodologia.

A coleta iniciou-se com o questionário fechado como forma de pré-teste, para que tivéssemos uma estimativa sobre futuros resultados. Logo depois houve discussões sobre motivação nas aulas de língua inglesa e sobre o conhecimento dos alunos acerca de videoclipes e suas funcionalidades no cotidiano, em que foi apresentado um videoclipe para discussão inicial, e as respostas e a interatividade dos alunos foram registradas nas notas de campo dos pesquisadores.

A atividade escrita em grupos envolvendo um videoclipe específico foi o próximo instrumento aplicado como forma de coletar dados sobre a aprendizagem com o uso de estratégias, assim como observar o comportamento deles diante da atividade proposta.

E, por fim, a entrevista foi utilizada como pós-teste, a fim de verificar se houve êxito nas atividades e quais os pontos de vista dos aprendentes em relação ao ensino de língua inglesa com videoclipes e sobre a motivação, assim como verificar outros possíveis métodos para trabalhar com o videoclipe em sala de aula.

A aplicação do questionário como pré-teste vem valorizar o corpus desta pesquisa e despertar na análise comparações dos dados obtidos, a capacidade de dialogar com discussões na perspectiva dos letramentos sendo "o conjunto de práticas sociais mediadas pela leitura e/ou pela escrita" (SOUZA; CORTI; MENDONÇA, 2012, p.15), e dos multiletramentos que, segundo Rojo (2013) são práticas que envolvem multiplicidade de linguagens, semioses e mídias envolvidas e a pluralidade e a diversidade cultural. Na atualidade há novos estudos de letramentos nas práticas socioculturais de linguagem, a conjugação de ações de leitura com a determinação e funcionalidade, nos permitindo o uso do videoclipe como instrumentos dentro destas práticas multiletradas. Com base nessas práticas, elaboramos o questionário, composto por sete (07) questões objetivas, que serão apresentadas a seguir com suas respectivas análises, para que houvesse um reconhecimento prévio sobre as vivências dos aprendentes de língua inglesa em relação a práticas mediadas pelo uso de mídias, principalmente o videoclipe. 
A primeira questão do questionário condiz com a preferência dos aprendentes quando se trata de videoclipes em língua inglesa, independente de estilo musical. O objetivo dessa questão foi analisar inicialmente se eles tinham contato com o gênero. Percebemos que treze (13) alunos (50\%) afirmaram assistir videoclipes em inglês regularmente, enquanto que oito (08) alunos (31\%) afirmaram assistir, porém com pouca frequência. Já cinco (05) alunos (19\%) não assistem videoclipes em língua inglesa. Como podemos perceber, o uso do gênero videoclipe encontra-se presente no cotidiano dos aprendentes, em que oitenta e um por cento (81\%) tem contato, representando assim a possibilidade de uso do mesmo como instrumento de ensino da língua inglesa na sala de aula, visto que há novas relações multiculturais de forma globalizada, trazendo assim grandes inferências para o aprendente durante a aquisição e ampliando os significados através do visual.

A intenção da segunda pergunta do questionário era considerar apenas os que afirmaram assistir videoclipes em inglês, revelando se eles procuravam saber traduções ou interpretações acerca dos videoclipes que assistiam. Nesta pergunta, apresenta-se uma constante no que diz respeito sobre o uso do videoclipe para compreensão da língua inglesa. Em comparação com a primeira pergunta, pode-se perceber que houve uma pequena redução na porcentagem em relação aos que assistem videoclipes para os que utilizam o videoclipe para compreender a língua inglesa, representado por cinquenta e sete por cento (57\%), percentual este que se eleva ao acrescentar os quarenta e três por cento (43\%) que às vezes buscam compreender, nos revelando que, mesmo assim, ainda há o uso de videoclipes em seu cotidiano no intuito de assimilar a língua inglesa por mais que não seja frequente, pois estão também relacionados ao uso das novas Tecnologias de Informação e Comunicação - TIC -, e que pode-se inserir estes em sala de aula e explorar para o auxílio no aprendizado de língua inglesa.

$\mathrm{Na}$ terceira pergunta, as categorias foram organizadas de acordo com a quantidade de meios de comunicação que os alunos utilizam para assistir videoclipes. A maioria (54\%), que correspondem a quatorze (14) alunos, utilizam apenas o celular para ter acesso à essa mídia. Sete (07) alunos ainda responderam que utilizam o celular e também o computador (27\%), que ficam em segundo lugar como sendo as mídias mais utilizadas. Dois (02) alunos afirmaram que utilizam apenas o computador para ter acesso aos videoclipes (7\%), enquanto um (01) apenas utiliza a TV como meio de assistir o gênero (4\%). Outros dois (02) alunos utilizam TV, computador, DVD e celular para assistir (8\%).

Assim, apresenta-se o uso massivo das novas TIC (celulares, principalmente) entre eles. A importância dessa pergunta é verificar quais os níveis de acesso dos alunos às tecnologias, e também os tipos de suportes utilizados para ter acesso aos videoclipes, independente da classe social, que de acordo com a afirmação de Rojo:

Não bastasse o fato de as TICs permitirem que os sujeitos da periferia entrem em contato com práticas de texto antes restritas aos grupos de poder, eles ainda possibilitam e potencializam a divulgação desses textos por meio de uma rede complexa, marcada por fluidez e mobilidade, que funciona paralelamente às mídias de massa. (ROJO, 2013, p.8)

De qualquer forma, os aprendentes utilizam algum meio para ter acesso aos videoclipes, o que torna as evidências positivas em relação ao contato dos alunos com as mídias fora da instituição escolar.

A questão quatro era apenas levantar dados quantitativos em relação ao número de vezes que esses indivíduos têm contato com o gênero. Sobre assistir videoclipes em um tempo de dois meses, cinco (05) alunos (19\%) assistiram de um a três videoclipes, dois (02) alunos 
(8\%) assistiram de quatro a seis videoclipes, um (01) aluno (4\%) assistiu de sete a nove videoclipes, quatro (04) alunos (15\%) assistiram de dez a doze videoclipes, um (01) aluno (4\%) assistiu de quinze a dezessete videoclipes, nove (09) alunos (35\%) assistiram mais de vinte videoclipes e quatro (04) alunos (15\%) afirmaram não ter assistido videoclipes em inglês. Assim, noventa e seis por cento (96\%) dos alunos já assistiram pelo menos um ou mais videoclipes em inglês. Isso retoma o que Dionisio (2011) discorreu sobre letramento visual, em que está relacionado com a organização social das comunidades, no caso, os jovens. Eles organizam os gêneros textuais de acordo com sua cultura, de forma que eles consigam entendê-los, utilizando seus próprios meios para construir sentidos. Portanto, se eles buscam assistir videoclipes mensalmente, é porque já faz parte de seu cotidiano assistir videoclipes, já que fazem parte da cultura de massa que traz consigo diversas tecnologias que permitem o acesso aos videoclipes.

A questão cinco representa um de nossos incentivos da realização desta pesquisa, que tem o intuito de verificar se os alunos participantes já tiveram contato com videoclipes nas aulas de língua inglesa. Mais da metade dos alunos (54\%) já trabalharam em sala de aula com o gênero, e a outra metade (46\%) ainda não tiveram a oportunidade de utilizar o videoclipe nas aulas. Percebe-se que temos quantidades consideráveis de alunos que ainda sequer trabalhou com esse gênero em sala de aula até mesmo antes do ensino médio. Melo; Oliveira; Valezi (2012) afirmam que

\begin{abstract}
A educação ainda tem muito o que fazer em termos de estrutura física e de capacitação dos professores, mas não podemos ignorar o quanto as novas práticas discursivas decorrentes das tecnologias de informação estão atraindo os alunos para uma nova realidade social. Mesmo com tantas lacunas na estrutura arquitetônica e humana do sistema educacional brasileiro, as práticas de linguagem da alta modernidade, cada vez mais presentes no cotidiano social dos alunos, impulsionam o professor a promover ainda mais mudanças em sua ação docente como vistas a garantir maior motivação e bons resultados no desenvolvimento dos nossos alunos. (MELO; OLIVEIRA; VALEZI, 2012, p.147-148).
\end{abstract}

Os motivos de ainda não terem contato com o videoclipe nas aulas de língua inglesa seriam a falta de equipamentos, de infraestrutura adequada (salas de vídeo, por exemplo), falta de capacitação dos professores para trabalhar com esse gênero e até falta de profissionais da área.

A sexta questão tem como objetivo verificar com aqueles que tiveram contato com videoclipes nas aulas de língua inglesa durante toda sua vida estudantil, se estes souberam identificar os motivos do professor (a) estar utilizando aquele gênero em sala de aula. Dois (02) alunos (14\%) responderam que não houve a explicação do porquê da utilização do videoclipe, e os que afirmaram sobre a explicação (36\%), segundo os dados obtidos através das discussões e que constam nas anotações de campo, havia apenas o trabalho de tornar a aula mais atrativa utilizando apenas como objeto de entretenimento, que elencava com atividades gramaticais ou apenas trabalhar o aspecto fonético, na qual eles deveriam repetir as palavras para depois cantar. E há os que não recordam (50\%) sobre os temas das aulas em que foram utilizados os videoclipes. Se o aluno alega não lembrar do que foi exposto em uma aula, então ele provavelmente não internalizou os conhecimentos passados em sala de aula. Dörnyei (2001a) já havia falado sobre os desafios para a boa receptividade dos alunos, sejam provenientes da interação, comportamento e dos objetivos que os próprios aprendentes escolhem, pois isso influencia na aprendizagem, e daí a importância de gerar a autonomia. 
Esses dados mostram a grande responsabilidade do professor no uso de videoclipes como instrumento de ensino-aprendizagem da língua inglesa, no qual confirma a não exploração deste gênero, devendo assim a responsabilidade do professor em dar uma resposta positiva ao aprendente, contextualizando as práticas de linguagens aos recursos midiáticos, cabendo a ele moldar suas práticas com os aprendentes para que a aprendizagem e a motivação se torne mais efetiva, utilizando ambientes interativos de uso da língua inglesa.

A sétima e última questão do questionário foi fundamental para a pesquisa, pois questiona sobre forma como os aprendentes veem o videoclipe no ensino da língua inglesa, que importância atribuem ao gênero, mostrando o interesse dos aprendentes na utilização de videoclipes. Vinte e dois (22) alunos (96\%), sendo a maioria, acham importante o uso do videoclipe nas aulas de língua inglesa, enquanto que quatro (04) alunos (4\%) se mostraram indecisos para responder essa questão. Isso demonstra o forte engajamento por parte dos aprendentes em explorar esse gênero multimodal, mesmo os que não tiveram aulas com a utilização de videoclipes, demonstrando a relevância dessa pesquisa na busca da motivação desses aprendentes, já que nenhum destes respondeu que não acha importante a utilização dos videoclipes nas aulas.

As notas de campo foram primordiais para registrar e analisar o comportamento dos aprendentes em relação à motivação, seguidas das perguntas feitas a eles no primeiro dia de coleta de dados. Pudemos verificar por meio da discussão o nível dos aprendentes em relação à língua inglesa, seus anseios em relação à disciplina e sobre o cotidiano destes fora da instituição escolar em que têm contato com a língua inglesa. Logo após, apresentamos o gênero videoclipe através do vídeo "Pretty Hurts", da cantora Beyoncé, em que foram feitos questionamentos sobre sua estrutura, funcionalidades e sobre a utilização destes para aprender a língua inglesa. A discussão foi dividida em três blocos de perguntas.

No primeiro bloco, abordamos a questão da motivação, sobre o conhecimento prévio da área e sobre os interesses dos aprendentes. Já no segundo bloco, iniciamos a discussão sobre o gênero videoclipe e sobre a utilização deles no cotidiano. E o terceiro bloco coloca em prática todos os conhecimentos prévios dos aprendentes para que eles consigam interpretar o videoclipe utilizando estratégias.

Por exemplo, sobre a pergunta "Vocês acham que fora da escola vocês têm contato com a língua inglesa? De que forma?", muitos responderam através das músicas. Alguns alunos ressaltaram sobre algumas mídias em que se encontra a língua inglesa

\footnotetext{
AP2: Podemos ver o inglês nas propagandas... nos outdoors... nos videogames. A palavra 'play' significa jogar. Tem também no computador, tudo quase é em inglês, e eu que fiz curso de informática, meu professor disse para estudarmos pelo menos o básico de inglês porque no computador é só assim.
}

AP1: As redes sociais como Facebook, Whatsapp, Twitter... tudo que rola na Internet tá em inglês, as vezes muitos recorrem ao Google Tradutor pra entender alguma coisa.

No que condiz a convivência desses indivíduos ao mundo informatizado, já esperávamos respostas como essas, pois é impossível ignorar que cada vez mais os jovens têm contato com diversas mídias, que por vezes são utilizadas simultaneamente. O potencial que essas mídias têm em relação a língua inglesa é grandiosa, e por isso os videoclipes se inserem nesse grande arsenal de aprendizagem, visto que também circulam nesse meio. Rojo (2012, p.24) chama estas mídias de "ferramentas colaborativas", que estão inseridas dentro dos 
multiletramentos para que haja não apenas interatividade, mas colaboração entre eles. Assim, para o aprendizado da língua inglesa, o aprendente pode se utilizar dessas diversas mídias que ele tem contato, não se prendendo apenas a uma para conseguir assimilar a língua.

Em uma pergunta do segundo bloco, os participantes foram questionados sobre quando assistiam videoclipes em inglês, se eles conseguiam entender o tema sem atentar para a letra da música. As respostas e as justificativas foram variadas

AP17: Só consigo entender se o videoclipe não estiver confuso, porque tem vários que não tem nada a ver com a letra. É só para escutar e dançar.

AP7: Eu consigo entender porque eu entendo o tipo de música dos meus ídolos. As vezes são músicas que vem com temas para reflexão, e então consigo entender algumas palavras.

AP2: Os videoclipes que assisto geralmente são para mostrar algum tema. Como eu gosto de Rock, tem também aqueles que é só para mostrar a banda tocando mesmo.

A importância dessa pergunta foi para esboçar, de alguma forma, quais as estratégias que esses alunos utilizam para entender a língua inglesa, mesclando a forma oral com a forma visual para chegar a um consenso interpretativo.

O videoclipe "Pretty Hurts" da cantora Beyoncé traz um tema polêmico e negativo em meio aos concursos de beleza, em que muitas pessoas se submetem a vários procedimentos em busca da perfeição. Não tão somente para os concursos de beleza, mas reflete na vida de muitos jovens, porque há um padrão de beleza na sociedade que obriga muitos a seguir, mesmo que arrisque sua própria saúde. Por isso, levamos para a sala de aula um videoclipe em que o tema é conhecido pela maioria dos jovens, mesmo eles desconhecendo o estilo musical, a cantora ou até o próprio videoclipe.

Depois de assistirem o videoclipe, foi feita a primeira pergunta acerca do tema sem atentar a letra da música em que esse estavam em mãos. "Busca pela beleza", "anorexia", "perfeição", "brigas", "desentendimentos", "tristeza", "cirurgia plástica" e "concurso de beleza" foram expressões utilizadas por alguns alunos para colocar, em linhas gerais, o entendimento da temática apenas visualizando passagens do videoclipe.

Atentando agora para a forma oral, ou seja, a música em si, perguntamos quais frases ou vocábulos fizeram com que eles entendessem a temática. A intenção era observar e nivelar os conhecimentos já adquiridos por eles acerca da língua inglesa. Algumas frases como "You're a pretty girl", "Perfection is the disease of a nation" $\mathrm{e}$ "Are you happy with yourself?" foram as três frases que foram mais pontuadas. Quando perguntados sobre o que significava, alguns alunos fizeram algumas considerações

AP1: Percebi que essas são frases com o verbo to be. Então, para mim, foi fácil de perceber isso.

AP7: Eu só prestei atenção nas palavras mama, pretty, happy, perfection. Acho que elas resumem bem todo o vídeo.

Os alunos que se posicionaram eram aqueles que já tinham contato com a língua inglesa, então foi mais viável a ativação do conhecimento prévio para que respondessem as 
perguntas. O’Malley e Chamot (1990) discorre sobre esse tipo de estratégia cognitiva, na qual há de transferência de informações, em que se utiliza conhecimentos linguísticos conhecidos para facilitar a tarefa de aprendizagem.

Então, percebemos que ao longo da discussão, as respostas para a última pergunta iam aparecendo (sobre vocábulos conhecidos e desconhecidos), como a do AP7, que colocou as palavras mama, pretty, happy e perfection como conhecidas por ele. Então, achamos necessário explorar os aspectos linguísticos que eles já reconheciam, como o trabalho com cognatos e inferências.

Os alunos foram pontuando as palavras que conheciam, em que houve uma categorização de vocábulos que tinham a terminação -tion: question, aspiration, perfection, nation, reflection, illusion. Então, perguntamos o significado de cada palavra e todos os alunos souberam traduzir, e após questionamos como eles sabiam, e eis que surgiram duas respostas significativas:

AP2: Essas palavras são muito parecidas com a língua portuguesa, não é?

AP7: O final de cada palavra corresponde ao final -ção do Português. Pode ver assim, questÃO, perfeiçÃO, naçÃO...

O que pretendemos mostrar é que não precisaram recorrer a nenhum tipo de elemento externo para que eles chegassem a essas conclusões, como livros, dicionários ou aplicativos, e sim apenas exercitaram suas habilidades de raciocínio e dedução.

A atividade escrita foi um exercício de análise interpretativa do videoclipe "Firework" de Katy Perry. O objetivo dessa ação é motivar os alunos a buscar a compreensão da temática do videoclipe através de inferências e deduções, sem precisar recorrer totalmente à gramática normativa, além de promover estratégias que auxiliem na compreensão de determinadas frases e vocábulos - entenda-se como cognatos e compound nouns. A bateria de perguntas serviu como uma ferramenta para identificarmos e facilitarmos essas capacidades nos alunos: a utilização de estratégias para o aprendizado de novas palavras individualmente e em grupo, uma vez que a turma foi disposta em equipes para a solução do exercício, para que observassem e a captassem a temática através de visão interpretativa e uso de métodos de dedução e inferência para compreensão da língua inglesa.

A terceira questão "Quais as passagens fizeram com que vocês chegassem à conclusão da temática do videoclipe?", por exemplo, tem um cunho mais direto em relação ao contexto visual e a relação com a temática do videoclipe. Agora, a análise torna-se linear e apenas pede citações dos trechos do vídeo que auxiliaram na resolução da primeira questão e incentiva os grupos que responderam à pergunta baseada na tradução literal a compreender melhor o tema empregado. A felicidade (ou falta dela) foi um objeto comum entre as respostas, enquanto algumas se ativeram a trechos do vídeo:

GRUPO D: As pessoas felizes com os fogos de artificio, por todos os lados. Demonstrando felicidade.

GRUPO C: O clipe retrata a realidade uma família que possui problemas, uma jovem que se sente excluída, um adolescente com câncer, uma pessoa sendo agredida na rua. 
Com esta parte do exercício, os aprendentes são incentivados a utilizar a repetição através da memorização e agrupamento, ambos contidos na teoria de estratégias cognitivas de O’Malley e Chamot (1990). O agrupamento vem como um método para auxiliar também na realização de feedbacks, já há a organização das informações sobre o videoclipe.

A entrevista foi aplicada após a atividade escrita, como a última bateria de questões a que os aprendentes seriam submetidos. De natureza mista, a entrevista apresenta questões subjetivas e de múltipla escolha a respeito das aulas e ações desenvolvidas em sala de aula no período em que estivemos coletando os dados para essa pesquisa.

Diante do posicionamento positivo da classe, os aprendentes foram incentivados a apontar quais os fatores que os motivaram a prestar atenção e gerar interesse pelo estudo da língua inglesa.

\begin{tabular}{|l|c|}
\hline \multicolumn{1}{|c|}{ Aspectos motivadores da aula } & $\begin{array}{c}\text { Quantas vezes } \\
\text { citaram }\end{array}$ \\
\hline Música & 4 \\
Abordagem dos professores & 7 \\
Videoclipe & 7 \\
Uso exclusivo de língua inglesa & 3 \\
Propostas de atividades & 1 \\
\hline
\end{tabular}

QUADRO 1 - Aspectos motivadores apontados pelos aprendentes

No quadro 1, pode-se observar algumas das justificativas dadas pelos aprendentes e a quantidade de citações. Ressaltamos que alguns alunos utilizaram mais de um aspecto e foi contabilizada uma citação para cada objeto discriminado. Um dos aspectos é a abordagem do professor, concordando com Dörnyei (2001a) sobre as estratégias motivacionais que envolvem o sucesso da aprendizagem.

A sexta questão da entrevista, que fecha a bateria de perguntas, cobra um posicionamento acerca da continuidade do uso de videoclipes como meio de aprendizado. $\mathrm{O}$ fundamento teórico para esta questão também está entre os posicionamentos de Dörnyei (2001a) que afirma que o professor, após a primeira interação motivacional, deve atentar-se para os interesses do aluno de modo a incentivar o crescimento constante, proteger a motivação e promover a auto-avaliação positiva com retrospectiva.

Desta vez, tivemos presença de posicionamentos adversos à técnica, por maior afinidade com o sistema tradicional de ensino, alguns alunos afirmaram que preferem estudar através de livros, por entender que assim há um aprendizado mais profundo. Os demais afirmaram que acharam a prática inovadora e interessante, portanto vão buscar significância para os videoclipes que vierem a assistir posteriormente.

AP19: Não! Apesar de ser bem legal e uma inovação, prefiro aprender através de livros e dicionários, estudar bem a língua inglesa através da gramática.

AP14: Creio que sim, me interessei muito mais na língua inglesa quando explicaram sobre como fazer para tentar entender as palavras na música. 
AP10: Sim, porque eu achei interessante essas aulas. O que mais chamou atenção, para mim, foi o fato de não ter me 'tocado' sobre as diversas coisas que estão perto de nós e está na língua inglesa, e que podemos aproveitar para aprender mais.

O fato do AP19 ter optado por não utilizar o videoclipe como instrumento para auxiliar em sua aprendizagem não anula em hipótese alguma a questão da motivação para que torne-se autônomo. Pelo exposto, ele possui estratégias também e, pelo seu discurso, interessa-se pela língua inglesa, já que opta pelo método tradicional de ensino-aprendizagem. Oxford (1990, p.9) aponta algumas características dessas estratégias individuais, já discorridas no Referencial Teórico, em que uma delas é a ampliação do papel do professor e a contribuição para a competência comunicativa. Assim, quando nos deparamos com aprendentes que já possuem suas próprias estratégias para aprender, o professor deve procurar desenvolver também suas habilidades de ensino, pois encontra-se sempre grandes potenciais em aprendentes autônomos.

\section{Considerações finais}

O estudo aqui apresentado teve como escopo verificar o uso do videoclipe contemporâneo como um instrumento multimodal na aprendizagem de língua inglesa, utilizando estratégias que levem o aluno à sua autonomia. Tal levantamento foi realizado por intermédio da aplicação de questionário, atividades e entrevista, os quais foram fundamentais para a coleta de dados analisados com base em um levantamento teórico acerca dos multiletramentos, multimodalidade, estratégias de aprendizagem e à busca de autonomia, a fim de aproximarmos as crenças coletadas dos indivíduos envolvidos, com o ambiente em que estão inseridas.

A escolha de videoclipes como tema de nossa pesquisa foi baseada no cotidiano dos alunos, na utilização de tecnologias que eles conhecem e manuseiam e em todas as experiências com diversas mídias e redes sociais em que transitam os videoclipes e a língua inglesa. Somado a isso, a facilidade de acesso a informação que a internet e meios de comunicação proporcionam atualmente, fortalecem a influência das produções norte americanas e, consequentemente, o contato com a língua inglesa, até mais que isso: a descoberta de preferência pelo vídeo no idioma original ao invés do dublado.

Toda essa situação levantou o questionamento sobre a eficácia do uso de recursos audiovisuais como instrumento de aprendizado de língua inglesa, teoria já desenvolvida por nomes como Lemke (2010[1998] apud ROJO, 2012), Rojo (2012, 2013), por exemplo, e que subsidiaram o nosso referencial teórico. Uma vez que é perceptível o gosto dos jovens pela língua inglesa, buscamos confirmar a efetividade do uso desse material constantemente utilizado pelo aluno.

Com o início da pesquisa de campo, foi notada a boa aceitação em grande parte dos alunos no trabalho com esse gênero, tanto nas discussões quanto nas atividades escritas que foram trabalhadas em grupo. Visto que pleiteávamos a eficiência do videoclipe no aprendizado através de inferência e dedução, a não utilização da gramática e de dicionários também foi algo em que parte dos alunos não esperava nas aulas, visto a linearidade do ensino na rede pública. E quando trabalhamos com aspectos de conhecimentos prévios, dedução, inferência e raciocínio lógico, os alunos tomaram novas estratégias para que aprendam a língua inglesa, bem como defendem O’Malley e Chamot (1990) quando discorrem sobre as estratégias de aprendizagem de língua inglesa. 
É notável a evolução dos meios de comunicação, cada vez mais integrados e modernos. Assim como esses recursos têm forte presença na rotina dos alunos, a escola também é uma porta para a entrada de diversas tecnologias e, por isso, deve se adaptar a essa evolução. O professor não pode se manter nos recursos básicos da educação, desconsiderando as novas tendências que atingem seus aprendizes, pois isso influencia diretamente no interesse pela disciplina e consequente resultado das aulas. Não desmerecemos as técnicas tradicionais de lecionamento, mas defendemos que o uso de recursos que condizem mais com a realidade do aluno têm maiores chances de prender a sua atenção e resultar em uma melhor compreensão do aprendizado. Assim, como deverá haver uma reflexão do docente acerca das potencialidades desses recursos, pois nada adiantará ter grandes mídias a disposição se não souber explorar da melhor forma possível.

Com base nesses resultados, foi possível clarificarmos a importância do conhecimento sobre estratégias e a contextualização do ensino, uma vez que são relevantes para o entendimento das expectativas do alunado no que concerne ao ensino-aprendizagem de língua inglesa, bem como os fatores externos influentes na construção da autonomia. Ademais, a partir do contato com o meio cultural dos alunos acerca da língua inglesa, possivelmente, muitos professores teriam um maior leque de informações para elaborarem suas metas de ensino.

Por fim, por meio deste estudo, buscamos contribuir para o ensino-aprendizagem da língua inglesa, uma vez que, tendo conhecimento das crenças dos alunos, sobre as diversas mídias que eles têm contato e as diversas práticas multiletradas advindas através desses gêneros, o professor poderá reavaliar suas práticas docentes, e os estudantes, por sua vez, estarão aptos a refletir sobre o seu papel enquanto estudantes de língua estrangeira e acerca da importância de se aprender uma nova língua.

\section{Referências}

ANDRÉ, M. E. D. A.. Etnografia da prática escolar. 18. ed. São Paulo: Papirus, 2012.

BAKHTIN, M. Os gêneros do discurso. In: Estética da Criação Verbal. [tradução feita a partir do francês por Maria Emsantina Galvão G. Pereira revisão da tradução Marina Appenzellerl. - 2. ed. São Paulo: Martins Fontes, 1997.— (Coleção Ensino Superior) $\begin{array}{lllll}\text { cap } & 3, & \text { p. } & \text { 277-289. } & \text { Disponível }\end{array}$ www.sistemas.ufrn.br/shared/verArquivo?idArquivo=1164092\&key> Acessado em 16 de jan. de 2016 às $13 \mathrm{~h} 00 \mathrm{~m}$.

DIAS, V. M. D. Hipercontos multissemióticos: para a promoção dos multiletramentos. . In: ROJO, R. Escol@ conectada: os multiletramentos e as TICs. 1. ed. São Paulo: Parábola Editorial, 2013. cap 5, p. 95-122.

DIONÍSIO, A. P. Gêneros textuais e multimodalidade. In: KARWOSKI, A. M. et al. Gêneros textuais: reflexões e ensino. 4. ed. São Paulo: Parábola Editorial, 2011. p. 137-152.

DÖRNYEI, Z. Motivational Strategies in the Language Classroom. Cambridge: Cambridge University Press, 2001.

GIL, A. C. Como elaborar projetos de pesquisa. 4. ed. São Paulo: Atlas, 2002.

MARCONI, M. A; LAKATOS, E. M. Metodologia científica. 6. ed. São Paulo: Atlas, 2011. 
MELO, E. S. O.; OLIVEIRA, P. W. M.; VALEZI, S. C. L. Gêneros poéticos em interface com gêneros multimodais. In: ROJO, R.; MOURA, E. Multiletramentos na escola. São Paulo: Parábola Editorial, 2012. cap 7, p. 147-164.

NETO, A. T. et al. Multiletramentos em ambientes educacionais. In: ROJO, R. Escol@ conectada: os multiletramentos e as TICs. 1. ed. São Paulo: Parábola Editorial, 2013. cap 7, p. $135-158$

O’MALlEY, J. M.; CHAMOT, A. U. Learning Strategies in Second Language Acquisition. 3rd ed. Cambridge: Cambridge University Press, 1993.

OXFORD, R. L. Language learning strategies: what every teacher should know.NBoston: Heinle \& Heinle, 1990.

ROJO, R. Gêneros discursivos do Círculo de Bakhtin e multiletramentos. In:

Escol@ conectada: os multiletramentos e as TICs. 1. ed. São Paulo: Parábola Editorial, 2013. cap 1, p. 13-36.

Pedagogia dos multiletramentos: diversidade cultural e linguagens na escola. In:_ ; MOURA, E. Multiletramentos na escola. São Paulo: Parábola Editorial, 2012. cap 1, p. 11-31.

SOUZA, A. L. S.; CORTI, A. P.; MENDONÇA, M. Letramentos no ensino médio. São Paulo: Parábola Editorial, 2012. 


\section{APÊNDICES}

APÊNDICE A - QUESTIONÁRIO FECHADO

\section{QUESTIONÁRIO}

Somos acadêmicos de Letras da UNIFAP, e estamos fazendo uma pesquisa sobre Videoclipes como estratégia para a aprendizagem da Língua Inglesa. Você pode colaborar?

NOME: TURMA:

PSEUDÔNIMO:

1- Você assiste videoclipes em inglês?

- Sim

○ Não

○ Às vezes

2- Se a resposta a questão anterior for "sim" ou "às vezes", você procura compreender o que dizem as músicas que você escuta/gosta?
o Sim
○ Não
○ Às vezes

3- Quais os meios de comunicação você utiliza para assistir videoclipes?
$\circ \mathrm{TV}$
○ Computador
○ DVD
- Celular
○ Blu-ray

4- Nos últimos dois meses, quantos videoclipes musicais (em inglês) você assistiu?
○ $1-3$ videoclipes
○ 10-12 videoclipes
o 4-6
o $12-14$ videoclipes
videoclipes
$15-17$ videoclipes
○ 18-19 videoclipes
- Mais de 20 videoclipes
○ Não assisti.

5- Durante toda a sua vida estudantil, você já teve alguma aula de língua inglesa em que o (a) professor (a) utilizou videoclipes?
○ Sim
○ Não

6- Se a resposta a questão 5 for "sim", o (a) professor (a) explicou sobre o porquê do uso do videoclipe?
○ Sim
○ Não
○ Não lembro

7- Você acha importante o uso do videoclipe para poder aprender mais a Língua Inglesa?
○ Sim
○ Não sei
○ Não responder 


\section{APÊNDICE B - ATIVIDADE ESCRITA}

School: Prof. Gabriel Almeida Café

Students:

Class:

Date:

\section{ACTIVITY}

Após ter assistido o videoclipe Firework, da cantora Katy Perry, discutam e respondam as seguintes questões:

1) Qual é o tema ou a mensagem em questão contida no videoclipe?

2) Qual a influência que esse vídeo provoca com essa temática?

3) Quais passagens fizeram que vocês chegassem à conclusão da temática do videoclipe?

4) Listem 5 palavras-chave contidas na letra da música que expliquem a temática do vídeo.

5) Leia os trechos da música e expliquem de forma interpretativa sobre cada um deles:

a. "Ignite the light

And let it shine

Just own the night

Like the Fourth of July"

b. “Baby, you're a firework

Come on let your colors burst

Make 'em go, "Aah, aah, aah"

You're gonna leave them all in awe, awe, awe" 
c. 'You don't have to feel

Like a waste of space

You're original

Cannot be replaced" 


\section{APÊNDICE C - ENTREVISTA}

UNIVERSIDADE FEDERAL DO AMAPÁ

CURSO DE LICENCIATURA PLENA EM LETRAS

Nome:

Turma:

Pseudônimo:

\section{ENTREVISTA}

1. Você gostou das aulas com os videoclipes? Por quê?

2. Você se sentiu motivado para aprender inglês a partir da utilização dos videoclipes? Por quê?
- Sim
○ Não
○ Não sei responder

3. Se a resposta anterior for sim, quais os aspectos nas aulas que motivaram você a aprender inglês?

4. Você acha que a utilização do videoclipe é uma boa estratégia para aprender inglês? Por quê?

5. Depois das aulas com videoclipes, você buscará aprender a língua inglesa através de algum outro videoclipe? Por quê? 
